\title{
El Factor de Impacto como medida de relevancia en la Investigación Clínica
}

La investigación clínica o aplicada en medicina surge principalmente de una pregunta que nos hacemos durante nuestra práctica clínica diaria. Sin embargo, no todas estas preguntas pueden ser contestadas correctamente a partir de la investigación. Es más, una pregunta de investigación debe de cumplir una serie de requisitos antes de proseguir con el proceso científico necesario para dar con su respuesta. Estos requisitos son: viabilidad, interés (del investigador), novedad, ética y relevancia. El último de estos requisitos, la relevancia, está directamente relacionada con lo que denominamos factor o índice de impacto (del inglés Impact Factor) que es la forma de medir la importancia, entendida como adquisición de nuevo conocimiento, de nuestra pregunta de investigación cuando ha sido contestada.

Este factor de impacto es un índice creado por Eugene Garfield (fundador del Institute for Scientific Information. ISI) y basado en el número de veces que se citan los artículos de una revista. Si, por ejemplo, las citas recogidas en 2006 sobre artículos publicados en una revista concreta en los dos años anteriores sumasen 995 y el número de artículos publicados por esa revista en esos dos años fuese de 258, su factor de impacto en el año 2006 sería de 3.857. Esto es, 995/258 $=3.857$. Por lo tanto si una revista obtiene una media de una cita por artículo, su factor de impacto será 1 , mientras que si sus artículos son citados menos de una vez de media, su factor de impacto estará por debajo de 1. Revistas con altos factores de impacto son, por ejemplo, Science: 30,028; Nature: 26,681; The Lancet: 25,800 o BMJ: 9,245. Entendiendo que el factor de impacto de las revistas no es estático y tiende a cambiar cada año. Revistas editadas en castellano y con factor de impacto son, por ejemplo, Medicina Clínica: 1,327 o Actas Españolas de Psiquiatría: 0,281 . Lógicamente los factores de impacto disminuyen cuando la revista se publica en un idioma distinto al inglés ya que sus artículos suelen ser poco citados en la inmensa mayoría de las revistas internacionales - publicadas en inglés - que cuentan con factor de impacto. Sin embargo, no todas las revistas obtienen un factor de impacto (sólo en biomedicina se han contabilizado más de 16000 revistas). Es más, llegar a pertenecer a ese selecto club del Journal Citation Reports, con un total de 7934 revistas especializadas incluidas, conlleva un importante esfuerzo editorial y muchos años de gestiones. En 2006, 32 revistas españolas (30 en la edición científica y 2 en la social) contaban con factor de impacto, -21 de ellas relacionadas con la biomedicina -, siendo la revista International Microbiology la que cuenta actualmente con un mayor índice de impacto: 2,455.

¿Es el factor de impacto una buena medida de la relevancia - importancia - de nuestra pregunta de investigación?

El factor de impacto es un índice muy controvertido en el campo de la investigación, ya sea ésta básica o clínica. Este índice cuenta con un amplio grupo de profesionales defensores de su aplicación, pero sin embargo también existe un amplio número de detractores. De los primeros, la mayoría normalmente publican con asiduidad en revistas de impacto medio-alto, mientras que dentro de los segundos, un importante porcentaje de ellos tiene bastantes problemas para publicar sus artículos en estas mismas revistas. Pecando de reduccionista por mi parte, tal vez sea este, y no otro, el motivo de la importante controversia que genera la aplicación de este estimador. No obstante, intentando buscar la equidad al hablar de este índice, nos siguen surgiendo ciertas dudas sobre su validez. Una de ellas es que el factor de impacto hace referencia a todos los artículos - en su conjunto - incluidos dentro de una revista, por lo que un artículo puede no ser citado nunca, y sin embargo estar publicado en una revista con un alto factor de impacto. Por el contrario, también se puede dar el caso de un artículo ampliamente citado, pero publicado en una revista de bajo impacto. Es más, en una revista es habitual que sólo unos cuantos artículos sean los que marquen su factor de impacto, es decir que se citen muy por encima del factor de impacto de la revista y de esta manera se compense con el resto de artículos - la mayoría - que apenas serán citados en los dos años siguientes. Esto indica que este estimador no parece mostrar la relevancia o importancia de una pregunta de investigación sino la relevancia de la revista donde se publica la respuesta a una determinada pregunta de investigación.

¿Existen otros indicadores más adecuados, a nivel internacional, para medir la relevancia de una pregunta de investigación? 
Como hemos comprobado, el factor de impacto no mide directamente la relevancia de un artículo o autor concreto. Para este fin, podemos utilizar un índice creado por un catedrático de física de la Universidad de California, Jorge Hirsch, denominado índice "h". Este índice es un balance entre el número de publicaciones de un investigador y las citas que han recibido éstas publicaciones. En esencia, lo que intenta medir este índice es la calidad de un investigador, separando investigadores con importante influencia en sus campos de trabajo - a partir de sus publicaciones de investigadores que simplemente publican muchos artículos. Así, con este índice se puede medir la calidad y producción científica de un investigador y por lo tanto determinar la relevancia de sus preguntas de investigación. Sin embargo, también este índice está sujeto a críticas, por ejemplo, que un investigador joven no puede tener un índice $\mathrm{h}$ alto o que el autor de un trabajo singular y muy citado podría tener un índice $\mathrm{h}$ pequeño.

Lo expuesto anteriormente trata de mostrar que actualmente no es fácil determinar la relevancia o importancia de una pregunta de investigación a partir de los estimadores cuantitativos utilizados habitualmente en el mundo científico. Es más, si nos centramos en biomedicina tendríamos que añadir ciertas "variables de confusión" que complican sustancialmente este tema. Por ejemplo, que los datos negativos de intervenciones terapéuticas o preventivas se han estado publicando durante mucho tiempo en revistas preferentemente de bajo factor de impacto o incluso no han pasado de ser un abstract o comunicación con- gresual. Esto, que se denomina sesgo de publicación, hace referencia a que en algunos casos intereses no científicos (comerciales, profesionales) modifican la relevancia o el impacto de una pregunta de investigación - la relevancia debería de ser independiente del resultado, positivo o negativo, de una investigación -. Otra variable de confusión que nos invita a reflexionar sobre este tema son los pagos por publicidad que ingresan las revistas con altos factores de impacto y que chocan frontalmente con la posible publicación, por muy relevante que sea, de manuscritos que concluyen en dirección opuesta a la ofertada en esa publicidad. Siguiendo con estas variables de confusión, las instituciones donde se realizan las investigaciones y los apellidos de los investigadores son, en algunos casos, condicionantes más importantes para la publicación de manuscritos, que la relevancia de la propia pregunta de investigación.

Sin embargo, y a pesar de los inconvenientes y "peculiaridades" comentadas anteriormente, las revistas con factor de impacto son un adecuado medio de diseminación internacional de los resultados de una investigación. Y sin querer buscar la perfección en este instrumento de medida, el investigador español debe de entrar a formar parte de la nómina de autores que publican en revistas de alto factor de impacto para, sólo a posteriori, poder obtener la acreditación necesaria para la crítica y mejora del método.

José Luis Rodríguez Martín Jefe del Área de Investigación Clínica de FISCAM 